\title{
Prevention of surgical site infections after brain surgery: the prehistoric period to the present
}

\author{
Elizabeth Carroll, MD, ${ }^{1}$ and Ariane Lewis, MD ${ }^{1,2}$ \\ Departments of ${ }^{1}$ Neurology and ${ }^{2}$ Neurosurgery, NYU Langone Medical Center, New York, New York
}

\begin{abstract}
In this historical vignette, the authors discuss the prevention of surgical site infections (SSIs) after brain surgery from the prehistoric period to the present. Although the mechanism for infection was not fully understood until the 19th century, records demonstrate that as early as $10,000 \mathrm{BC}$, practitioners used gold, a biocidal material, for cranioplasties and attempted to approximate wounds by tying a patient's hair across the incision. Written records from the Egyptian and Babylonian period depict the process of soaking head dressings in alcohol, an antibacterial agent. In the Greek and Early Byzantine period, Hippocrates argued against the formation of pus in wounds and continued to champion the use of wine in wound management. In the 16th century, intracranial silver drains were first utilized in an effort to prevent postoperative infections. The turning point of SSI prevention was in 1867, when Joseph Lister illustrated the connection between Louis Pasteur's discovery of the fermentation process and the suppuration of wounds. Today, there are ongoing investigations and debates about the optimal techniques to prevent SSI after brain surgery. Although tremendous progress in the field of SSI prevention since the prehistoric period has been made, SSI continues to affect morbidity and mortality after brain surgery.
\end{abstract}

https://thejns.org/doi/abs/10.3171/2019.5.FOCUS19250

KEYWORDS history; surgical site infection; prevention

$\mathrm{A}$ PPRECIATING the fund of knowledge and resources available to minimize the risk of surgical site infections (SSIs) after brain surgery in the 21st century requires an understanding of the history of SSI prevention. Herein, we review the history of SSI prevention from the initial days of brain surgery in the prehistoric period to the present (Table 1).

\section{The Prehistoric Period}

The earliest report of a neurosurgical procedure dates back to the prehistoric period when, in 10,000 BC, trephination was performed. ${ }^{12,24}$ Akin to the modern burr hole, the indication for trephination in the prehistoric period remains unclear to historical scholars. Nonetheless, a number of skulls obtained from this era that show evidence of trephination demonstrate premorbid bone healing at the site of the incision, suggesting patients survived this procedure. $^{12,24}$ Far ahead of their time, it appears that practitioners who performed trephination during this period may have recognized what is now known as the biocidal effect of heavy metals, as evidenced by their use of gold in cranioplasties. ${ }^{12}$ Additionally, it appears that they attempted to approximate wounds for improved healing by tying patients' hair across both sides of the incision..$^{24}$

\section{The Egyptian and Babylonian Period (3000 BC to $30 \mathrm{BC}$ )}

With the invention of the written word came the first documentation of medical and surgical literature, most notably the Ebers Papyrus, Hearst Papyrus, and Edwin Smith Papyrus. ${ }^{12}$ According to these documents, the Egyptian practice of medicine was based largely on magic and superstition, but, despite this, their contributions to cranial surgery are important. As written in the Edwin Smith Papyrus (ca. 1700 BC), the Egyptians utilized skull sutures and designed head dressings for cranial injury. This is the first record of wound dressings specific to the head.12

Around the same time the Edwin Smith Papyrus was written, the Sumerians recorded the first account of attempted wound management and prevention of SSI. Surgeons cleansed wounds with beer and then bandaged them with a cloth soaked in wine and turpentine, suggesting an understanding of ethanol's antibacterial properties. ${ }^{26}$

\section{The Greek and Early Byzantine Period (500 BC to $\mathrm{AD} 700$ )}

Although trephination was performed for thousands of years before the Greek and Early Byzantine period, the 
TABLE 1. Timeline of SSI prevention techniques after brain surgery

\begin{tabular}{|c|c|}
\hline Period & Prevention Technique \\
\hline Prehistoric period & $\begin{array}{l}\text { - Gold (a biocidal agent) was used for cranio- } \\
\text { plasty inlay }\end{array}$ \\
\hline $\begin{array}{l}\text { Egyptian \& Babylonian } \\
\text { period }\end{array}$ & $\begin{array}{l}\text { - The first use of head dressings was } \\
\text { recorded in the Ebers, Hearst, \& Edwin } \\
\text { Smith papyri } \\
\text { - Alcohol (beer \& wine) was used by the } \\
\text { Sumerians to cleanse wounds }\end{array}$ \\
\hline $\begin{array}{l}\text { Greek \& early Byzan- } \\
\quad \text { tine period }\end{array}$ & $\begin{array}{l}\text { - Hippocrates taught that the formation of pus } \\
\text { was not a natural component of the healing } \\
\text { process } \\
\text { - Claudius Galen argued the formation of pus } \\
\text { was essential for wound healing }\end{array}$ \\
\hline Islamic Golden Age & $\begin{array}{l}\text { - Haly Abbas recommended wine-soaked } \\
\text { dressings for head wounds } \\
\text { - Albucasis pioneered the use of catgut for } \\
\text { improved wound healing }\end{array}$ \\
\hline Middle Ages & $\begin{array}{l}\text { - Rogerius Salernitanus described the need } \\
\text { to change head dressings twice a day in } \\
\text { winter \& } 3 \text { times a day in summer } \\
\text { - Theodoric Borgognoni advised the avoid- } \\
\text { ance of "laudable pus," revitalizing Hip- } \\
\text { pocrates' views } \\
\text { - Guy de Chauliac recommended shaving the } \\
\text { head before surgery to prevent hair from } \\
\text { interfering with wound healing }\end{array}$ \\
\hline 16th-18th centuries & $\begin{array}{l}\text { - Ambroise Paré advocated against pouring } \\
\text { boiling oil into wounds \& favored the use of } \\
\text { turpentine (an antiseptic) \& egg yolk (which } \\
\text { is high in zinc) to promote wound healing } \\
\text { - Sauveur François Morand utilized tubes } \\
\text { made of silver (an antimicrobial agent) to } \\
\text { drain cerebral abscesses }\end{array}$ \\
\hline 19th \& 20th centuries & $\begin{array}{l}\text { - Joseph Lister drew the connection between } \\
\text { fermentation \& suppuration of wounds \& } \\
\text { developed an "antiseptic gauze" } \\
\text { - Oliver Wendell Holmes \& Ignaz Philipp } \\
\text { Semmelweis encouraged the practice of } \\
\text { handwashing with aseptic solutions } \\
\text { - Alexander Fleming discovered penicillin \& } \\
\text { it began to be used both intravenously \& } \\
\text { intrathecally intraoperatively }\end{array}$ \\
\hline 21 st century & $\begin{array}{l}\text { - Infection prevention bundles came into } \\
\text { vogue } \\
\text { - Debate persists about the need for pro- } \\
\text { longed prophylactic antibiotics in patients } \\
\text { with intracranial drains/devices, the best } \\
\text { EVD catheter, \& the optimal frequency of } \\
\text { CSF sampling from EVDs }\end{array}$ \\
\hline
\end{tabular}

first formal development of neurosurgery occurred in the golden age of Greece. The neurosurgical patient population was plentiful there, given the frequent head trauma suffered by soldiers at war on the battlefield and gladiators in competition in the arena. ${ }^{12}$

The majority of medical documentation from this time is attributed to Hippocrates, who wrote about localization of injury to the brain and provided details on trephination and wound management. ${ }^{12}$ In regard to infection prevention, Hippocrates was the first to report that the formation of pus was not a natural component of the healing process and should be avoided. Similar to the Sumerians, he recommended cleansing wounds with wine, applying a bandage, and then pouring more wine on the bandage itself. ${ }^{26}$

Unfortunately, Hippocrates' novel teachings about the implications of pus were considered controversial. Given the high prevalence of infected wounds at the time, it was often thought that suppuration, the process of pus formation, was a healthy part of healing, and the idea that pus should be avoided was frowned upon. ${ }^{26}$ Claudius Galen, a surgeon to the gladiators, was a prominent opponent of Hippocrates' views on pus. Galen argued that the formation of pus was essential for wound healing ${ }^{26}$ in fact, his followers were taught to introduce salve and plaster into wounds to promote healing. ${ }^{27}$ Although Hippocrates was exalted during this period for some of his other contributions to medicine, it was Galen's doctrine on suppuration that remained the rule for wound management until the 19th century. ${ }^{26}$

Another notable contributor of this era is Paul of Aegina, who is considered the last of the great Byzantine physicians. Paul of Aegina is credited with designing a number of neurosurgical tools and early manuscripts depicting sophisticated insight on wound management. Similar to Hippocrates, he utilized wine as an antiseptic and recommended applying a dressing that did not put pressure on the brain. ${ }^{12}$

\section{The Islamic Golden Age (AD 800 to AD 1400)}

The Islamic Golden Age bred two physicians who left an enduring impact on the world of surgery, Haly Abbas and Albucasis. Haly Abbas, a Persian physician, drew much of his knowledge from Paul of Aegina's writings. His legacy was The Perfect Book of the Art of Medicine, in which he dedicated 100 chapters to surgical practice. In his writings, he described the use of wine-soaked dressings for head wounds. ${ }^{12}$

The second scholar who contributed to the field of SSI prevention after neurosurgical procedures during this period was Albucasis. He wrote The Clearance of Medical Science For Those Who Can Not Compile It, a comprehensive, well-illustrated text designed to teach others the art of medicine. This book referenced a multitude of neurosurgical diagnoses and treatments, including head injuries, skull fractures, and spinal injuries, and the types of wound dressings that should be used for each. ${ }^{4}$ While little attention was paid to spinal injuries prior to his time, he argued that to assist in wound healing in spinal injuries, all bone fragments in the spinal canal should be removed. In addition, he pioneered the use of catgut for internal stitching for improved wound healing, a practice that is still used today. ${ }^{4}$

\section{The Middle Ages (AD 400 to AD 1400)}

Although still centuries prior to the age of antisepsis, infection prevention in the field of neurosurgery blos- 
somed in Medieval Europe thanks to the brilliant minds of Rogerius Salernitanus, Theodoric Borgognoni, Leonard of Bertapalia, and Guy de Chauliac.

Rogerius Salernitanus, the first writer on surgery in Italy, provided readers specific instructions surrounding wound management after skull fracture. He wrote,

When there is considerable fracture to the skull associated with a large open wound ... any fragment of bone or other substance should be removed and a fold of the finest linen should then be gently insinuated with a feather between the skull and the dura mater (to clean the wound). The external wound should be covered with pieces of linen soaked in white of egg and lightly rung out over which a dressing of down should be placed and carefully bandaged, the dressings should be changed twice daily in winter and three times in the summer. ${ }^{7}$

Theodoric Borgognoni of Cervia was considered a pioneer in the use of aseptic technique. Although his method is not the aseptic technique we utilize today, his ideas were still impressive given that his teachings were based upon the avoidance of "laudable pus." His technique directly contradicted the teaching of Galen, which was the standard of care at the time, and revitalized Hippocrates' views on the evils of pus. Borgognoni described the ideal conditions for wound healing, including control of bleeding, removal of contaminated or necrotic material, avoidance of dead space, and careful application of a wound dressing bathed in wine. ${ }^{12}$

Of a similar school of thought was Leonard of Bertapalia, who argued that one should avoid materials that might cause pus, avoid compressive dressings, and remove bone and debris that pierced the brain. ${ }^{12}$ Although the danger of purulent wounds is now widely known, Hippocrates, Beorgognoni, and Leonard of Bertapalia were denounced by their colleagues, given that their views contradicted $\mathrm{Ga}-$ len's doctrine of suppuration. ${ }^{26}$

At the end of the Middle Ages, Guy de Chauliac added to the contributions of his predecessors. In his writings on head injury, he recommended that the head be shaved prior to surgery to prevent hair from interfering with wound healing and suggested that wine be placed into depressed skull fractures to assist in healing. He categorized head wounds into 7 types, including hollowed wounds, contused wounds, and ulcerated wounds, and made recommendations on intervention and wound management based on wound classification..$^{9,12}$ Though his positive contributions to prevention of neurosurgical infection were substantial, de Chauliac unfortunately followed the teachings of Galen and supported the idea that suppuration was essential to wound healing. ${ }^{27}$

\section{The 16th to 18th Century}

One of the most influential scholars during the 16th century was Ambroise Paré, considered by many to be the father of modern surgery. Paré emphasized that all foreign bodies be removed from a wound and advocated against a practice that was quite common at the time: pouring boiling oil into wounds. He instead made dressings of egg yolk, rose oil, and turpentine, which greatly reduced SSI. ${ }^{2}$

Less than 200 years after Paré, Sauveur François Morand, a French surgeon, described one of the earliest op- erations for treatment of a cerebral abscess. He noted that he explored the abscess with his finger, removing as much of the purulent content as possible, and instilled balsam and turpentine into the cavity prior to dressing it. He also described placing a silver tube for drainage, which he then slowly removed as the wound healed. Impressively, Morand recognized 1) silver's effectiveness in wound healing before the knowledge of its antimicrobial properties, and 2 ) the importance of allowing the continued drainage of an intracerebral cavity. ${ }^{12}$

Despite the fact that a select few scholars appreciated the importance of wound management and infection prevention before the 19th century, it is worth noting that the majority of healthcare providers did not pay attention to cleanliness during this period. As described in a lecture by Thomas Vicary,

In some cases, the more filthy the surroundings - eg the surgeon's coat - the better pleased the surgeon appeared to be! Further, a post-mortem examination was not seldom attended, and perhaps fingered immediately before the performance of an operation; and as the surgeon would naturally attend an autopsy on the surgical case it would not be unlikely that the cause of death would be erysipelas or some other form of sepsis. ${ }^{7}$

\section{The 19th to 20th Century}

Similar to those who came before them, early 19th century physicians who recommended the prevention of suppuration were looked down on by the greater medical community. Most notable among the 19th century opposition to suppuration were Oliver Wendell Holmes and Ignaz Philipp Semmelweis. Both Holmes and Semmelweis recognized the importance of handwashing; Holmes recommended physicians wash their hands with a calcium chloride solution after autopsy, while Semmelweis encouraged the practice of handwashing with chloride lime solution. ${ }^{26}$

SSI remained a major cause of death throughout the 19 th century, with nearly $80 \%$ of operations plagued by "hospital gangrene." 26 Stephen Smith, a surgeon at Bellevue Hospital between 1850 and 1880, described the unsanitary conditions of the time. In regards to infection control, he reported that 1) neurosurgical patients often had their hair shaved, but the skin of the scalp was seldom cleaned; 2) surgeons came straight from the autopsy suite to the operating room without cleaning their hands; and 3) for educational purposes, bare-handed bystanders in the operating room were encouraged to "take a feel" within the wound of both intracranial injuries and spinal injuries. ${ }^{25,28}$ During this period, the same sponge was used to clean the wounds of multiple patients, and bandages were often reused without washing. Additionally, operating theaters were adorned with tables that were rarely cleaned, with sawdust on the floor to absorb spilled body fluids. ${ }^{2}$

In April 1867, infection prevention was forever changed with Joseph Lister's (a British surgeon) publication on antisepsis, which illustrated the connection between Louis Pasteur's discovery of the fermentation process and the suppuration of wounds. Lister wrote, "all the local inflammatory mischief and general febrile disturbance which follow severe injuries are due to the irritating and poisoning influence of decomposing blood or sloughs." ${ }^{26}$ Just 
a few of his advances include the use of an "antiseptic gauze" with oakum and carbolic acid, the latter of which had been used to purify sewage in a nearby town, and the assertion that dressings should be changed prior to becoming soaked. ${ }^{27}$

Joseph Lister's introduction of antisepsis to the operating room was a major turning point in infection prevention, and, finally, the medical community was willing to listen. Following his publication came the introduction of heat sterilization by Ernst von Bergmann, the creation of sterile gowns and caps by Gustav Neuber of Kiel, the invention of the surgical mask by Mikulicz, and popularization of rubber gloves by William Stewart Halsted after he commissioned Goodyear to develop them for his nurses. ${ }^{26}$

William Keen, a pioneer in American neurosurgery, strongly advocated for the use of listerian antiseptic techniques. Keen's surgical setup as described by James Stone was as follows:

\begin{abstract}
All carpets and unnecessary furniture were removed from the patient's room. The walls and ceiling were carefully cleaned the day before operation, and the woodwork, floors, and remaining furniture were scrubbed with carbolic solution. This solution was also sprayed in the room on the morning preceding but not during the operation. On the day before the operation, the patient's head was shaved, scrubbed with soap and water, and ether, and covered with wet corrosive sublimate dressing until operation, then ether and mercuric chloride washing were repeated. The surgical instruments were boiled in water for 2 hours and new deep-sea sponges (elephant ears) were treated with carbolic and sublimate solutions before usage. The surgeon's hands were cleaned and disinfected by soap and water, alcohol, and sublimate solution. $^{26,30}$
\end{abstract}

Wound care also advanced during the 19th century. In a lecture given in 1895, the surgeon Emory Lanphear described the need to protect the brain from becoming infected by the presence of foreign bodies, and remarked that antiseptic precautions with packing must be taken, with all packing removed at a maximum of 48 hours after insertion. ${ }^{17}$

Fewer than 100 years after Lister's groundbreaking publication, the field of infection prevention was again propelled forward markedly in 1929 , with the release of Alexander Fleming's accidental discovery of penicillin. ${ }^{12}$ By the 1940s, physicians began to report the use of prophylactic intravenous penicillin intraoperatively, and by the 1960s, it was being administered intrathecally prophylactically. $12,14,27$

\section{The 21st Century}

Based on the advances of the 18th and 19th centuries, the World Health Organization currently recommends a number of steps be taken to avoid SSI after brain surgery, including patient preparation prior to surgery, handwashing, and surgical site preparation. ${ }^{3}$ Many hospitals have implemented bundles to reduce SSI, which include measures such as preoperative chlorhexidine gluconate (CHG) shampoo, preoperative CHG-alcohol skin prep, perioperative antibiotics, postoperative incision care orders, and a glycemic control protocol. ${ }^{22}$ Despite this, SSI is still a prevalent issue worldwide, although it is the most prevent- able healthcare-associated infection. ${ }^{3,8,23}$ Reported rates of SSI vary greatly, but the literature shows the rates of neurosurgical SSI in the average practice generally range between $1 \%$ and $9 \%{ }^{1,21}$ There is an ongoing quest to identify the optimal means to prevent SSI after brain surgery; multiple studies have addressed infection prevention in patients with intracranial drains or monitors, but practice still varies. ${ }^{3,18,19}$

A few aspects of SSI prevention that practitioners continue to investigate and debate include 1) the need for prolonged prophylactic antibiotics in patients with external ventricular drains (EVDs), intracranial monitors, and subdural/subgaleal drains; ${ }^{18,29,31,35}$ 2) the best EVD catheter, ${ }^{6,13,15,33-35}$ and 3) the optimal frequency of CSF sampling from EVDs. ${ }^{5,32,33}$ Although some authors advocate for the use of prophylactic systemic antibiotics after placement of intracranial drains and devices, others argue this practice does not affect the rate of SSI and is harmful because it increases the risk of growth of resistant gramnegative pathogens and the development of Clostridium difficile. ${ }^{10,11,16,19,20,22,25}$ Regarding EVD catheter selection, a survey of members of the Neurocritical Care Society found that many institutions use conventional catheters despite the fact that evidence suggests antibiotic-impregnated EVDs and silver-impregnated EVDs do a better job of preventing SSI. ${ }^{13,15,19,22,31,35}$ Lastly, the optimal frequency of CSF sampling to assess for SSI is debated; while some practitioners only sample CSF on an as-needed basis based on the principle that frequent sampling can increase the risk of SSI, others perform routine sampling in an effort to diagnose and subsequently treat SSI quickly. ${ }^{19,22,32}$

\section{Conclusions}

Since the earliest neurosurgical procedures in the prehistoric period, practitioners have attempted to avoid SSI. In some cases, theories about infection prevention were controversial, or incorrect, but there has been tremendous progress in avoiding postoperative infections after brain surgery. Nonetheless, we still do not have all the answers, and patients continue to develop SSIs after brain surgery leading to morbidity and mortality. We must remain diligent and continue to analyze data on infection prevention techniques to ensure that we do not repeat history and embrace any strategies such as suppuration that induce harm, rather than benefit. Additionally, we must ensure that we 1) protocolize infection prevention practices, 2) enforce compliance with both general medical and institutionspecific guidelines, 3) perform surveillance for infections, and 4) educate practitioners about infection prevention strategies as we strive to eradicate SSI after brain surgery.

\section{References}

1. Adeleye AO: Low rates of post-craniotomy surgical site infections in a developing country: surgical technique and results. Br J Neurosurg 32:136-140, 2018

2. Alexander JW: The contributions of infection control to a century of surgical progress. Ann Surg 201:423-428, 1985

3. Allegranzi B, Bischoff P, de Jonge S, Kubilay NZ, Zayed $\mathrm{B}$, Gomes SM, et al: New WHO recommendations on preoperative measures for surgical site infection prevention: an evidence-based global perspective. Lancet Infect Dis 16:e276-e287, 2016 
4. Amr SS, Tbakhi A: Abu Al Qasim Al Zahrawi (Albucasis): pioneer of modern surgery. Ann Saudi Med 27:220-221, 2007

5. Arabi Y, Memish ZA, Balkhy HH, Francis C, Ferayan A, Al Shimemeri A, et al: Ventriculostomy-associated infections: incidence and risk factors. Am J Infect Control 33:137-143, 2005

6. Babu MA, Patel R, Marsh WR, Wijdicks EFM: Strategies to decrease the risk of ventricular catheter infections: a review of the evidence. Neurocrit Care 16:194-202, 2012

7. Ballance C: The Thomas Vicary Lecture: being a glimpse into the history of the surgery of the brain. Lancet 199:165172,1922

8. Berríos-Torres SI: Evidence-based update to the U.S. Centers for Disease Control and Prevention and Healthcare Infection Control Practices Advisory Committee Guideline for the Prevention of Surgical Site Infection: developmental process. Surg Infect (Larchmt) 17:256-261, 2016

9. Bullough VL: Chauliac, Guy De, in Gillispie CC (ed): Complete Dictionary of Scientific Biography. New York: Charles Scribner's Sons, 1971

10. Camacho EF, Boszczowski I, Freire MP, Pinto FCG, Guimaraes T, Teixeira MJ, et al: Impact of an educational intervention implanted in a neurological intensive care unit on rates of infection related to external ventricular drains. PLoS One 8:e50708, 2013

11. Chatzi M, Karvouniaris M, Makris D, Tsimitrea E, Gatos C, Tasiou A, et al: Bundle of measures for external cerebral ventricular drainage-associated ventriculitis. Crit Care Med 42:66-73, 2014

12. Goodrich JT: Landmarks in the history of neurosurgery, in Ellenbogen RG, Sekhar LN, Kitchen N, et al (eds): Principles of Neurological Surgery, ed 4. Philadelphia: Elsevier, 2018, pp 3-36

13. Keong NCH, Bulters DO, Richards HK, Farrington M, Sparrow OC, Pickard JD, et al: The SILVER (Silver Impregnated Line Versus EVD Randomized trial): a double-blind, prospective, randomized, controlled trial of an intervention to reduce the rate of external ventricular drain infection. Neurosurgery 71:394-404, 2012

14. Keong NCH, Gleave JRW, Hutchinson PJ: Neurosurgical history: comparing the management of penetrating head injury in 1969 with 2005. Br J Neurosurg 20:227-232, 2006

15. Konstantelias AA, Vardakas KZ, Polyzos KA, Tansarli GS, Falagas ME: Antimicrobial-impregnated and -coated shunt catheters for prevention of infections in patients with hydrocephalus: a systematic review and meta-analysis. J Neurosurg 122:1096-1112, 2015

16. Korinek AM, Baugnon T, Golmard JL, van Effenterre R, Coriat P, Puybasset L: Risk factors for adult nosocomial meningitis after craniotomy: role of antibiotic prophylaxis. Neurosurgery 59:126-133, 2006

17. Lanphear E: Lectures on intracranial surgery: VI-brain tumor and its surgical treatment. JAMA 24:613-616, 1895

18. Lewis A, Czeisler BM, Lord AS: Prolonged prophylactic antibiotics with neurosurgical drains and devices: Are we using them? Do we need them? Am J Infect Control 44:17571758,2016

19. Lewis A, Czeisler BM, Lord AS: Variations in strategies to prevent ventriculostomy-related infections: a practice survey. Neurohospitalist 7:15-23, 2017

20. Lewis A, Sen R, Hill TC, James H, Lin J, Bhamra H, et al: Antibiotic prophylaxis for subdural and subgaleal drains. J Neurosurg 126:908-912, 2017

21. López Pereira P, Díaz-Agero Pérez C, López Fresneña N, Las Heras Mosteiro J, Palancar Cabrera A, Rincón Carlavilla ÁL, et al: 'Epidemiology of surgical site infection in a neurosurgery department.' Br J Neurosurg 31:10-15, 2017

22. Lord AS, Nicholson J, Lewis A: Infection prevention in the neurointensive care unit: a systematic review. Neurocrit Care 31:196-210, 2019

23. Mangram AJ: A brief overview of the 1999 CDC Guideline for the Prevention of Surgical Site Infection. J Chemother 13:35-39, 2001

24. Marino R Jr, Gonzales-Portillo M: Preconquest Peruvian neurosurgeons: a study of Inca and pre-Columbian trephination and the art of medicine in ancient Peru. Neurosurgery 47:940-950, 2000

25. May AK, Fleming SB, Carpenter RO, Diaz JJ, Guillamondegui OD, Deppen SA, et al: Influence of broad-spectrum antibiotic prophylaxis on intracranial pressure monitor infections and subsequent infectious complications in head-injured patients. Surg Infect (Larchmt) 7:409-417, 2006

26. Miller JT, Rahimi SY, Lee M: History of infection control and its contributions to the development and success of brain tumor operations. Neurosurg Focus 18(4):e4, 2005

27. Morton JJ: The struggle against sepsis. Yale J Biol Med 31:397-422, 1959

28. Protas M, Schumacher M, Iwanaga J, Yilmaz E, Oskouian RJ, Tubbs RS: Treatment of gunshot wounds to spine during late 19th century. World Neurosurg 115:285-287, 2018

29. Sonabend AM, Korenfeld Y, Crisman C, Badjatia N, Mayer SA, Connolly ES Jr: Prevention of ventriculostomy-related infections with prophylactic antibiotics and antibiotic-coated external ventricular drains: a systematic review. Neurosurgery 68:996-1005, 2011

30. Stone JL: W. W. Keen: America's pioneer neurological surgeon. Neurosurgery 17:997-1010, 1985

31. Wang X, Dong Y, Qi XQ, Li YM, Huang CG, Hou LJ: Clinical review: efficacy of antimicrobial-impregnated catheters in external ventricular drainage - a systematic review and meta-analysis. Crit Care 17:234, 2013

32. Williams TA, Leslie GD, Dobb GJ, Roberts B, van Heerden PV: Decrease in proven ventriculitis by reducing the frequency of cerebrospinal fluid sampling from extraventricular drains. J Neurosurg 115:1040-1046, 2011

33. Williamson RA, Phillips-Bute BG, McDonagh DL, Gray MC, Zomorodi AR, Olson DM, et al: Predictors of extraventricular drain-associated bacterial ventriculitis. J Crit Care 29:77-82, 2014

34. Wong GKC, Ip M, Poon WS, Mak CWK, Ng RYT: Antibiotics-impregnated ventricular catheter versus systemic antibiotics for prevention of nosocomial CSF and non-CSF infections: a prospective randomised clinical trial. J Neurol Neurosurg Psychiatry 81:1064-1067, 2010

35. Zabramski JM, Whiting D, Darouiche RO, Horner TG, Olson $\mathrm{J}$, Robertson C, et al: Efficacy of antimicrobial-impregnated external ventricular drain catheters: a prospective, randomized, controlled trial. J Neurosurg 98:725-730, 2003

\section{Disclosures}

The authors report no conflict of interest concerning the materials or methods used in this study or the findings specified in this paper.

\section{Author Contributions}

Conception and design: both authors. Acquisition of data: Carroll. Analysis and interpretation of data: both authors. Drafting the article: Carroll. Critically revising the article: both authors. Reviewed submitted version of manuscript: both authors. Approved the final version of the manuscript on behalf of both authors: Carroll.

\section{Correspondence}

Elizabeth Carroll: NYU Langone Medical Center, New York, NY. elizabeth.carroll@nyulangone.org. 